\title{
Knowledge and attitudes of Al-Baha elementary school teachers (health care educators) regarding emergency treatment of avulsed permanent teeth
}

\begin{abstract}
Objective: The aim of this study was to examine teachers (health care educators) knowledge and attitudes about avulsed permanent teeth and their emergency treatment in children.

Methods: A total of 27 teachers of AL-Baha elementary schools were included in the study. Questionnaires were used to collect data on teacher's demographic characteristics, previous training in traumatic dental injury and treatment and knowledge of avulsed permanent teeth and their emergency management.
\end{abstract}

Results: Most of the participants $(66,6 \%)$ reported that they would replant the avulsed tooth in its socket, and almost half of them (55.5\%) gave correct answers regarding the optimum time for which an avulsed tooth should be left out of the mouth prior to replantation. However, most teachers $(70,37 \%)$ were not sufficiently familiar with the appropriate method for cleaning a dirty avulsed tooth. The demographic characteristics effects on the teacher's knowledge couldn't be statistically estimated due to the limitation of the sample size

Conclusion: This study showed that the teacher's level of knowledge about the management of avulsion in children is insufficient and that educational courses are essential to provide proper management of tooth avulsion.

Keywords: avulsion, teacher's knowledge, Al-Baha school, dental trauma
Volume 5 Issue I - 2016

\author{
Mohammed AL Zahrani, Hamed Eid AL Kalaf \\ Student at college of health sciences, Al-Baha University, Saudi \\ Arabia
}

Correspondence: Mohammed AL-Zahrani, Endodontic consultant at MOH,Al-Baha Dental Center, Saudi Arabia, Email sarhan_212@yahoo.com

Received: July 26, 2016 | Published: September 14, 2016

\section{Introduction}

Dental trauma occurs commonly in children and adolescents that would affects teeth and/or their supporting structures. ${ }^{1}$ Many studies have reported prevalence rates of dental trauma to be between $4.9 \%-37 \%{ }^{2,3}$ One of the most complicated dental trauma injuries is tooth avulsion. ${ }^{4}$ Avulsions constitute $0.5 \%-16 \%$ of all dental trauma injuries ${ }^{2}$ and most often includes the upper central incisor. ${ }^{4}$ Avulsion might occur at any age, however the most common age for avulsion is between $8-12$ years of age, a time during which periodontal ligament is loosely structured and provides minimal resistance to an extrusive force ${ }^{4}$ Proper management and early intervention is necessary for the best long term prognosis of avulsed tooth, particularly in children. ${ }^{4}$ Ideally, an avulsed tooth should be replanted immediately in order to avoid further injury to the periodontal ligament. ${ }^{4}$ The prognosis of a replanted avulsed tooth depends on the period of time elapsed before replantation, the storage medium, the stage of root development and the amount of contamination. ${ }^{1}$ Therefore, it is important that the teachers, who are among those most often present when an injury occurs, are aware of the proper ways for management of avulsion. Although various studies have been published to evaluate teacher's knowledge and attitudes regarding management of avulsed teeth, ${ }^{5-7}$ to the best of our knowledge, no study has been conducted among AL-Baha school teachers. Therefore, this study aimed to investigate teacher's knowledge and attitudes regarding avulsed permanent teeth and their emergency treatment in children in AL-Baha, kingdom of Saudi Arabia.

\section{Materials and methods}

A total of 27 teachers (school health care educators) of ALBaha elementary schools were included in the study. Participation in the study was voluntary and completely confidential. The study instrument consisted of a questionnaire that was filled by the researcher after conducting telephonic interviews with teachers. Actually 50 contact numbers of different school teachers (health instructors) were provided by the (administration of education in AlBaha region) but unfortunately 27 of them accepted our request to participate in the research. The questionnaire was designed to collect data on educational level; previous training in dental trauma; and knowledge of avulsion and their immediate management. Collected data was analyzed statistically but unfortunately the sample size was not enough to determine the impact of the demographic characteristics on the level of knowledge of the teachers with different levels of education.

\section{Results}

Educational levels of respondents are given in (Table 1). Educational levels of teachers. Responses to questions related to teachers' perceived knowledge and attitudes regarding dental trauma are given in (Table 2). Most teachers $(88.8 \% ; n=24)$ reported that they had never received any information about traumatic dental injuries, only $3.7 \%(\mathrm{n}=1)$ of teachers had obtained knowledge about dental trauma from a dentist. While most of teachers $(62.9 \%, n=17)$ said they had inadequate information about dental trauma, 33.3\% $(\mathrm{n}=9)$ 
of the respondents said having information about traumatic dental injuries was very important. Responses to questions related to specific knowledge of emergency management of avulsed tooth injuries are given in (Table 3). Many $66.6 \%(n=18)$ of the teachers reported that they would replant an avulsed tooth in its socket. When asked what type of media was best for storing an avulsed tooth until a dental professional could be reached, most of the teachers $74 \%(n=20)$ chose physiological media (sterile saline, milk, saliva), whereas $3.7 \%(\mathrm{n}=1)$ chose non-physiological media (tap water) and the remaining $22.2 \%$ $(n=6)$ of respondents said they did not know which storage media was best. Only $25.9 \%(n=7)$ of respondents were able to identify the correct procedure for cleaning an avulsed tooth, whereas $74 \%(n=20)$ were unable to provide a proper answer regarding how to clean an avulsed tooth. When asked where they would take the injured child in the event of a dental trauma, $59.2 \%(n=16)$ said to dentist. Moreover, more than half of the participated teachers $55.5 \%(\mathrm{n}=15)$ knew the optimal time length within which to seek professional help for an avulsed tooth.

Table I Educational levels of respondents

\begin{tabular}{lll}
\hline Education Level & $\begin{array}{l}\text { Number of } \\
\text { Teachers }\end{array}$ & F Percentage \\
\hline Master & 18 & $66.60 \%$ \\
Bachelor & 7 & $25.90 \%$ \\
Diploma & 2 & 7.4 \\
\hline
\end{tabular}

Table 2 Teachers' perceived knowledge and attitudes regarding dental trauma

\begin{tabular}{|c|c|c|c|c|}
\hline Perceived knowledge & Response & & & \\
\hline \multirow{3}{*}{$\begin{array}{l}\text { Have you ever received any information regarding dental } \\
\text { trauma? }\end{array}$} & Yes & \multicolumn{3}{|l|}{ No } \\
\hline & 3 & \multicolumn{3}{|l|}{24} \\
\hline & $-11 \%$ & \multicolumn{3}{|l|}{$-89 \%$} \\
\hline \multirow{2}{*}{ What is your source of information? } & Ist aid course & Dentist & Family Physician & Others \\
\hline & I & 1 & 0 & I \\
\hline \multirow{3}{*}{$\begin{array}{l}\text { How would you evaluate your Information regarding } \\
\text { dental trauma? }\end{array}$} & Enough & Not Enough & I don't know & \\
\hline & 3 & 17 & 7 & \\
\hline & $-11 \%$ & $-63 \%$ & $-26 \%$ & \\
\hline \multirow{2}{*}{ Are you interested in learning more about dental trauma? } & Yes & To Some Extent & No & \\
\hline & $9(33.3 \%)$ & $8(29.6 \%)$ & $10(37 \%)$ & \\
\hline \multirow{3}{*}{$\begin{array}{l}\text { Do you like to be involved in education program about } \\
\text { dental trauma? }\end{array}$} & Yes & No & No Answer & \\
\hline & 18 & 8 & I & \\
\hline & $-66.60 \%$ & $-29.60 \%$ & $-3.70 \%$ & \\
\hline \multirow{3}{*}{ Did you ever experience tooth avulsion at school? } & Yes & No & & \\
\hline & 3 & 24 & & \\
\hline & $-11.10 \%$ & $-88.80 \%$ & & \\
\hline
\end{tabular}

Table 3 Teachers' knowledge regarding the immediate emergency management of avulsed permanent teeth

\begin{tabular}{|c|c|c|c|c|}
\hline Perceived knowledge & Response & & & \\
\hline \multirow{3}{*}{$\begin{array}{l}\text { Have you ever received any information regarding dental } \\
\text { trauma? }\end{array}$} & Yes & \multicolumn{3}{|l|}{ No } \\
\hline & 3 & \multicolumn{3}{|l|}{24} \\
\hline & $-11 \%$ & \multicolumn{3}{|l|}{$-89 \%$} \\
\hline \multirow{2}{*}{ What is your source of information? } & Ist aid course & Dentist & Family Physician & Others \\
\hline & 1 & I & 0 & 1 \\
\hline \multirow{3}{*}{$\begin{array}{l}\text { How would you evaluate your Information regarding } \\
\text { dental trauma? }\end{array}$} & Enough & Not Enough & I don't know & \\
\hline & 3 & 17 & 7 & \\
\hline & $-11 \%$ & $-63 \%$ & $-26 \%$ & \\
\hline \multirow{2}{*}{ Are you interested in learning more about dental trauma? } & Yes & To Some Extent & No & \\
\hline & $9(33.3 \%)$ & $8(29.6 \%)$ & $10(37 \%)$ & \\
\hline \multirow{3}{*}{$\begin{array}{l}\text { Do you like to be involved in education program about } \\
\text { dental trauma? }\end{array}$} & Yes & No & No Answer & \\
\hline & 18 & 8 & I & \\
\hline & $-66.60 \%$ & $-29.60 \%$ & $-3.70 \%$ & \\
\hline \multirow{3}{*}{ Did you ever experience tooth avulsion at school? } & Yes & No & & \\
\hline & 3 & 24 & & \\
\hline & $-11.10 \%$ & $-88.80 \%$ & & \\
\hline
\end{tabular}




\section{Discussion}

The prognosis for avulsed teeth is affected by proper treatment, which depends on the knowledge of care provider present at the site of an accident before professional dental care can be provided. ${ }^{4}$ since many incidents might occur at school, schoolteachers present are very important in providing appropriate care to the injured child. Although various studies have been published to evaluate teacher's knowledge and attitudes regarding management of avulsed teeth, ${ }^{5-7}$ to the best of our knowledge, no study has been conducted among AL-Baha school teachers. Therefore, this study aimed to investigate teacher's knowledge and attitudes regarding avulsed permanent teeth and their emergency treatment in children in AL-Baha, kingdom of Saudi Arabia. In harmony with the findings of similar studies conducted in other countries ${ }^{5-7}$ this study found teachers have insufficient knowledge regarding the emergency treatment of tooth avulsion. This can be explained by the fact that most teachers had not received enough information about traumatic dental injuries. In one positive finding, teachers indicated they were interested in learning more about dental trauma. Lack of knowledge about urgent management procedures for avulsed teeth may severely affect the prognosis; there is a real need for educational courses to improve the teacher's knowledge of management procedures for avulsed teeth. As table 3 shows, many of respondents $(66.6 \%)$ said they would replant an avulsed tooth in the alveolar socket, which is not completely in line with previous studies.$^{5-7}$ Few teachers were able to determine the appropriate way for cleaning an avulsed tooth prior to replantation, that is in agreement with earlier studies..$^{5-8}$ In the present study, 33.3\% of respondents stated that they would brush a dirty avulsed tooth before replanting it in its socket that is known to severely decrease the chance of achieving successful outcome. More than half of the respondents $(59.2 \%)$ stated that they would bring the injured child to the dentist following a traumatic dental injury. This reflects the awareness of the teachers; that the dentist is prepared to handle this type of patient. Several studies of outcomes of avulsed teeth have shown that the time elapsed between tooth avulsion and replantation, the higher the risk of replacement resorption and inflammatory root resorption. ${ }^{9}$ Whereas proper replantation of an avulsed tooth within 30 min has been demonstrated to have a $90 \%$ chance of success, ${ }^{8}$ only a very low chance $(5 \%)$ of long-term retention of an avulsed tooth exists if replantation occurs after $2 \mathrm{~h} .{ }^{8}$ It is discouraging to note that only $33.3 \%(n=9)$ of the teachers knew that professional help should be sought within $30 \mathrm{~min}$. of a traumatic incident. The ideal storage medium should be able to preserve cell vitality, and should be available at the site of the accident or easily accessible. ${ }^{10}$ If the tooth is transferred to a liquid medium such as milk, saline or the child's own saliva within the first 15 minutes following avulsion, the chance of preserving viable periodontal ligaments cells and cementum is higher which will play a role in regeneration. ${ }^{11}$ In this study, rather than physiological media, most teachers $(74 \%)$ correctly identify sterile saline, milk, or saliva as the best storage medium. Regardless of the education level teacher's knowledge of avulsed tooth management was found to be not enough. The important epidemiologic findings from the present study may serve as a useful source of information for the support of education and prevention strategies that will reduce the overall cost of treatment and insignificantly increase the chance of achieving a successful management. One of the advocated education strategies is the informative leaflet that showed improvement in all the categories of knowledge as a result of reading the leaflet and answering the questions..$^{12,13}$ One study showed a significant difference in the level of knowledge regarding dental trauma between the experienced and the inexperienced teachers. ${ }^{14}$

\section{Conclusion}

Since many traumatic dental injuries occur at school, the participation of schoolteachers in the emergency situation is essential to provide appropriate care to the injured child. Within the limitations of the present study, teachers were found to have a low level of knowledge regarding the emergency management policies of tooth avulsion and replantation. Knowledge of so should be increased by providing educational and preventive courses.

\section{Funding}

None.

\section{Acknowledgments}

None.

\section{Conflicts of interest}

Authors declare that there is no conflict of interest.

\section{References}

1. Santos ME, Habecost AP, Gomes FV, et al. Parent and caretaker knowledge about avulsion of permanent teeth. Dent Traumatol. 2009;25(2):203-208.

2. Schatz JP, Joho JP. A retrospective study of dento-alveolar injuries. Endod Dent Traumatol. 1994;10(1):11-14.

3. Wilson S, Smith GA, Preisch J, et al. Epidemiology of dental trauma treated in an urban emergency department. Pediatr Emerg Care. 1997;3(1):12-15.

4. Petrovic B, Marković D, Peric T, et al. Factors related to treatment and outcomes of avulsed teeth. Dent Traumatol. 2010;26(1):52-59.

5. Al-Jundi SH, Al-Waeili H, Khairalah K. Knowledge and attitude of Jordanian School health teachers with regards to emergency management of dental trauma. Dent Traumatol. 2005;21(4):183-187.

6. Caglar E, Ferreira LP, Kargul B. Dental trauma management knowledge among a group of teachers in two south European cities. Dent Traumatol. 2005;21(5):258-262.

7. Pacheco LF, Filho PF, Letra A, et al. Evaluation of the knowledge of the treatment of avulsions in elementary school teachers in Rio de Janeiro, Brazil. Dent Traumatol. 2003;19(2):76-78.

8. Arikan V, Sönmez H. Knowledge level of primary school teachers regarding traumatic dental injuries and their emergency management before and after receiving an informative leaflet. Dent Traumatol. 2012;28(2):101-107.

9. Ashkenazi M, Marouni M, Sarnat H. In vitro viability, mitogenicity and clonogenic capacity of periodontal ligament cells after storage in four media at room temperature. Endod Dent Traumatol. 2000;16(2):63-70.

10. Donaldson M, Kinirons MJ. Factors affecting the time of onset of resorption in avulsed and replanted incisor teeth in children. Dent Traumatol. 2001;17(5):205-209.

11. Huang SC, Remeikis NA, Daniel JC. Effects of long-term exposure of hu man periodontal ligament cells milk and other solutions. $J$ Endod. 1996;22(1):30-33. 
12. Ghaderi F, Adl A, Ranjbar Z. Effect of a leaflet given to parents on knowledge of tooth avulsion. Eur J Paediatr Dent. 2013;14(1):13-16.

13. Andreasen JO, Hjorting-Hansen E. Replantation of teeth. I. Radiographic and clinical study of 110 human teeth replanted after accidental loss. Acta Odontol Scand. 1966;24(3):263-286.
14. Junges R, Celeste RK, Pizzatto LN, et al. Elementary Schoolteachers' Knowledge and Decision-making Regarding Dental Trauma. Oral Health Prev Dent. 2015;13(4):357-364. 